\title{
EXPOSIÇÃO ÁGUA: UMA VIAGEM NO MUNDO DO CONHECIMENTO CIRANDA PELOS CAMPI DA USP: PRODUTOS E AVALIAÇÃO
}

*Elisabete de Santis Braga

\section{RESUMO}

A exposição itinerante "Água: uma viagem no mundo do conhecimento", do Museu de Ciências da USP, aborda um tema multidisciplinar dentro da década da "Água, fonte da vida" declarada pela Organização das Nações Unidas (ONU). A exposição itinerante obteve chancela da Unesco e apoio do CNPq. Ela representa um excelente veículo de extroversão do patrimônio científicocultural da USP e promove a articulação entre as unidades e órgãos da Universidade. A exposição foi concebida em módulos que permitem sua acomodação em diversos tipos de espaços disponíveis. Apresenta um formato voltado a uma forte aproximação do público. Encontra-se, atualmente, na $12^{\mathrm{a}}$ cidade de seu projeto de itinerância, tendo passado pelos campi da USP e também fora do estado de São Paulo, no Paraná. Registra um grande público (>50 mil visitantes), com mais de $50 \%$ de representação por escolares. A itinerância permitiu o treinamento e capacitação de jovens universitários e da comunidade extrauniversidade, promovendo parcerias entre a USP e as prefeituras e outros órgãos estaduais e municipais. A exposição ofereceu espaço para a inclusão e conhecimento de valores culturais e científicos locais, representando uma excelente experiência sociocultural e educativa em ambientes não formais.

Palavras-chave: Água. Exposição. Itinerância.

\section{ABSTRACT}

The itinerant exhibit Water: a trip in the world of knowledge from the Science Museum of the University of São Paulo (USP) that belongs to the Associate Dean's Office of Culture and Extension, discusses a multidisciplinary subject as a part of the Water for life decade proposed by UNO. It obtained Unesco's seal and CNPq's support. The exhibit presents an excellent way for exposing of the scientific-cultural heritage of the University and promotes the articulation between its units and organs. The exposition was created in a modular format that enabless an adaptation in many different space dispositions and allows a strong public approach. It is now settled at the I2th city in its traveling project, after having passed in every campi of the University, as well as having a passage out of São Paulo, in the state of Paraná. The display benefited more than 50.000 visitants with $50 \%$ of student representation. The project permitted the training and capacitating of young university students and the community, providing partnerships between USP and governmental agencies. It offered the opportunity for inclusion and knowledge of cultural and scientific local values, representing an excellent experience of socio-cultural and educative activity in informal education.

Key words: Exposition. Water. Itinerancy.

* Diretora do Museu de Ciências da Universidade de São Paulo (MC-USP). Endereço: Museu de Ciências. Av. Prof. Luciano Gualberto, trav. J, 374, $4^{\circ}$ andar, sala 422, Cidade Universitária - 05508-900 - São Paulo-SP - tel.: (II) 309I-3252 - e-mail: edsbraga@usp.br. 


\section{INTRODUÇÃO}

O Museu de Giências da Universidade de São Paulo (MG-USP), órgão da Pró-Reitora de Cultura e Extensão Universitária, foi criado em 2002 como um modelo diferenciado de museu de Giências. Ele visa promover a articulação entre os acervos criados e sob a guarda da Universidade de São Paulo, por meio de programas, eventos, exposições temporárias e itinerantes (CoCEx, 2002). Em seu projeto de criação, o Museu de Ciências da USP preocupou-se com a elaboração de uma exposição itinerante concebida sob um tema que pudesse ter abrangência multidisciplinar e pudesse também dar uma mostra da diversidade da Universidade de São Paulo em termos de áreas do conhecimento, interdisciplinaridade, acervos científicos e culturais de seu patrimônio.

A escolha do tema água para esta exposição veio de encontro com a importância desse patrimônio mundial nos tempos atuais e a versatilidade em sua abordagem atendeu ao caráter multidisciplinar e interdisciplinar necessário ao evento e, ainda, observou a recomendação da ONU quanto às discussões sobre o tema na década da Água-fonte da vida (2005-2015), declarada pelo Órgão. (ONU, 2003; 2005). No setor educativo, a Unesco lançou campanhas para a prática educativa no sentido de elucidar a situação da água no planeta e educar para o uso racional, e para a proteção deste patrimônio natural mundial.

A posição da Universidade de São Paulo como herdeira, geradora e mantenedora de um patrimônio científico-cultural variado, é a de não deixar de participar desta missão de conhecimento e valorização da água no planeta Terra. Assim, o Museu de Ciências da USP, com a colaboração de mais de 40 unidades e órgãos que integram o seu Conselho Deliberativo, gerou uma exposição itinerante temática, composta por materiais interativos, dioramas, minifilmes e minientrevistas científicas, que foram incorporados em computadores, televisores e narrativas que compõem a exposição, atendendo os mais atuais conceitos da museologia contemporânea e que integram a inteligibilidade e a beleza (WAGENSBERG, 2008), apresentada em um formato itinerante.

Ao longo de seus 75 anos, a Universidade de São Paulo herdou, adquiriu e gerou bens patrimoniais. Inúmeras coleções e acervos representantes das mais diversas áreas do conhecimento foram formados.
Museus foram incorporados e criados, com o intuito de valorizar e difundir este enorme patrimônio cultural e científico.

Exposições temporárias com temáticas unificadoras; gerenciamento de informação sobre acervos e coleções; ações educativo-culturais integradas; planos conjuntos de conservação preventiva; planos integrados de marketing e capacitação técnica especializada são exemplos de ações que o MG-USP deve empreender.

O MC-USP busca, por meio de programas de salvaguarda e comunicação, atuar como articulador de uma rede museológica de cooperação técnica e partilha de saberes, entre os demais órgãos e unidades da Universidade, além de central de difusão à sociedade, dos resultados destas parcerias. Desta forma, uma exposição elaborada sob uma temática que permite uma abordagem multidisciplinar, permitindo participações das Giências Exatas, Humanas, Biológicas, Artes e Tecnologia, representou um excelente ponto de partida às atividades do museu. O formato itinerante permitiu também a união entre os diversos campi da USP, localizados em várias cidades, como Ribeirão Preto, São Carlos, Pirassununga, Piracicaba, Bauru e localidades onde a USP possui atividade, como São Sebastião e Cananeia, estando programadas passagens por Lorena e pela Escola de Artes, Ciências e Humanidades. A exposição também representa o diálogo com a comunidade no formato de parcerias com prefeituras, secretarias de Educação, universidades particulares, entre outros, dentro de uma política de expansão e aproximação da Universidade com a sociedade.

O grande desafio constitui-se em conceber um modelo de exposição dentro dos moldes da multidisciplinaridade, do diálogo entre as ciências, as artes e a tecnologia, mostrando a universalidade da USP, para ser instalada em espaços com variados tamanhos e formas.

Os modelos atuais de apresentação de exposições chamam a atenção pela inserção de dispositivos artísticos e de novas tecnologias da comunicação na apresentação dos temas principais (MIRABITO, I998; SORIA, 200I). A demonstração experimental pode ser mantida, mas a beleza e as tecnologias são indispensáveis, tanto para o público estudantil como para o público geral. 


\section{MATERIAL E MÉTODOS}

Exposições temáticas multidisciplinares de ciências são de difícil concepção, pois o limite do espaço é uma importante forçante no tratamento de temas tão amplos e com tantas interfaces, como é o caso do tema água. Por outro lado, o tema é muito rico e atraente, dificultando também o recorte para apresentação.

A principal estratégia para a apresentação da exposição no formato itinerante proposta pelo $\mathrm{MC}$, foi a divisão em módulos, abrangendo as Ciências Exatas e da Terra, a Biologia, as Humanidades, as Artes e a Tecnologia, tendo como um forte diferencial o tratamento destes dois últimos itens, que estão normalmente fora dos moldes dos tradicionais museus e centros de ciência (DIAZ \& EGIDO, 2000). A inclusão de materiais interativos e atraentes foi mantida, porém, a presença de objetos de grande beleza artística, representa um importante agente catalisador no discurso expositivo.

Foi desenvolvido um modelo onde o tema é apresentado em módulos que remetem o visitante a situações relativas à água, desde seu aparecimento no planeta Terra até atingir as condições atuais do recurso natural, como essencial aos processos climatológicos, biológicos, artísticos e tecnológicos, dispondo os temas em conceitos essenciais produzidos especialmente para a exposição, retratados em peças centrais e utilizando recursos complementares dentro do próprio ambiente expositivo, e recursos satélites que ultrapassam o limite físico da exposição, modelo proposto pela coordenadora Profa. Dra. Elisabete Braga, em 2004 (figura I).

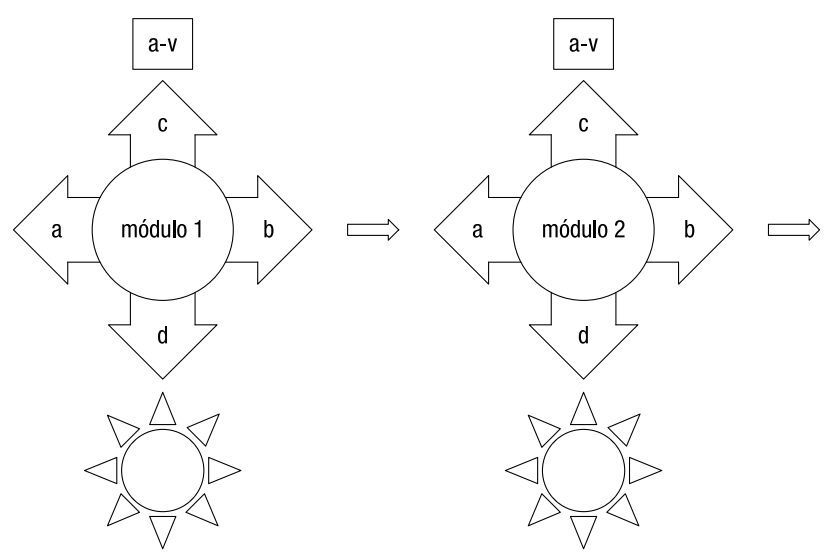

Figura I - Esquema proposto para a exposição água
A figura I apresenta o esquema proposto para a exposição, com base na disposição em módulos, que apresentam algumas peças distribuídas no espaço físico (a, b, c e d), dispositivo para apresentação de audiovisual (a-v) e dispositivo interativo e que permite visita e conhecimento de outros espaços e temas fornecendo também lista de páginas eletrônicas para consulta.

A disposição em módulos (figura I) e a apresentação de materiais em forma de multimídia foram concebidas de modo a transcender os espaços expositivos, despertando no visitante a busca voluntária por mais informações junto aos espaços USP e em outros "nichos de saber", localizados fora do espaço expositivo e tendo a oportunidade de conhecer páginas eletrônicas com informações certificadas, como é o caso das páginas das unidades e órgãos da USP.

A inserção de materiais e atividades relacionados aos valores científico-culturais locais é incentivada em cada local, bem como a formação e a capacitação de recursos humanos devem ser realizadas como contribuição da Universidade.

O material audiovisual e as atividades agregadas em cada cidade de itinerância são levados para o próximo local de exibição.

O envolvimento com a comunidade é feito por meio de visitas técnicas antes do início da exposição, onde são estabelecidas as parcerias e, nos casos fora da Universidade, são elaborados convênios, que asseguram a participação da comunidade junto à exposição. A capacitação dos recursos humanos locais, seja de alunos USP, seja de professores e alunos das cidades envolvidas, é um grande produto desta exposição.

Uma equipe de apoio é criada em cada cidade em que a exposição se apresenta, composta por indivíduos locais, professores, funcionários e outros, de modo a estabelecer a base de apoio durante a visitação.

Em cada cidade da itinerância, a exposição oferece pelo menos uma oficina de capacitação de monitores junto ao tema água, dos quais pelo menos três vão atuar junto à exposição com bolsa da USP ou remunerados localmente pela prefeitura ou outros parceiros envolvidos no processo. Há também a categoria de monitor voluntário, sem remuneração. No primeiro caso, a bolsa é paga via projeto, submetido ao Fomento às Iniciativas de Cultura e Extensão (antigo Fundo de Cultura e Extensão Universitária), onde pelo menos três bolsas são solicitadas pelo $\mathrm{MG}$ ou pelo campus 
parceiro para atuação dos monitores. No caso de outras cidades, a parceria com as prefeituras ou outros órgãos mantém a vigilância nos locais de exposição, bem como oferece como contrapartida, a contratação de monitores que passam pela oficina de treinamento para monitorar a exposição no período definido. Muitas vezes, alunos de outras faculdades são envolvidos no treinamento e monitoria.

A divulgação da Universidade ocorre de modo natural, como produto de uma parceria e aproximação com a sociedade.

\section{RESULTADOS}

\section{A EXPOSIÇÃO}

A exposição se desenrola em cinco blocos, onde é mostrado:

- Terra: um planeta especial porque tem água (figura 2, v. anexo);

- Terra: um planeta diferenciado porque tem água e vida (figura 3, v. anexo);

- Terra: um planeta diferenciado porque tem água, vida e civilização (figura 4 , v. anexo);

- Terra: um planeta diferenciado porque tem água, vida, civilização e tecnologia (figura 5, v. anexo);

- Terra: um planeta diferenciado que precisa de cuidados e preservação.

A figura 2 (v. anexo) expõe a temática do bloco I e uma vitrine, à direita, simbolizando a deriva continental com imagens cedidas pela associação de cartógrafos da França, o acoplamento entre os fluídos ar e água na formação do clima e as bacias hidrográficas da América do Sul, com destaque ao Aquífero Guarani. Vitrines emolduradas por imagens de satélite ampliadas cedidas pelo INPE.

A figura 3 (v. anexo) expõe a temática do bloco II, mostrando a origem da vida na sopa primordial, a molécula de DNA e vitrines com dioramas, simbolizando a água em diversos ecossistemas.

A figura 4 (v. anexo) expõe a temática do bloco III, mostrando a água e as civilizações, em vitrines que mostram a arquitetura, utensílios, mitologia e transporte ligados à água, com materiais artísticos feitos em papel no centro das peças. Detalhe de potes produzidos por ceramistas da cidade de São Sebastião (abaixo, à direita).
A figura 5 (v. anexo) expõe a temática do bloco IV, mostrando a passagem da água de recurso natural para recurso energético, representado por uma maquete animada de uma caldeira.

A figura 6 (v. anexo) expõe a temática do bloco $\mathrm{V}$, mostrando as grandes modificações na qualidade da água, em função de seus múltiplos usos e realçando a questão ambiental, mostrada por meio de uma grande maquete, toda feita artisticamente em papel, e protegida por uma redoma de acrílico.

Em cada bloco, a Universidade mostra sua participação e, no final, a missão da Universidade é reforçada junto à sustentabilidade deste recurso tão importante (figura 7, v. anexo).

Os materiais infográficos, dioramas, minifilmes, entrevistas, simuladores, vitrines e outras peças foram criados de modo original e segundo roteiro concebido pelo Museu de Ciências, sob a coordenação da Dra. Elisabete Braga. A geração de minifilmes didáticos voltados à passagem de conteúdo de cada bloco, foi um desafio trabalhado em parceria com a empresa contratada para a construção dos materiais.

A geração de entrevistas com personalidades da Universidade e das cidades anfitriãs ligadas ao tema água foram trabalhadas pela equipe do MG-USP, contando com o apoio de alunos da USP (ECA), sendo uma parceria inovadora onde os jovens profissionais de diversas áreas encontraram oportunidade de vivenciar experiências profissionais que contribuíram aos CVs, e firmaram a atuação do MC como local complementar à formação do aluno USP.

As parcerias com a TV Cultura e com a Sabesp também foram importantes, pois junto à primeira, o material cedido foi incorporado em cinco computadores espalhados na exposição, um em cada módulo. Em um home-theater localizado no final do roteiro expositivo, a versatilidade permite apresentação de filmes de diversas origens, incluindo um minifilme do $\mathrm{MC}$, o qual contém uma mensagem final otimista, de que todos podemos fazer muito pela preservação da qualidade da água no planeta Terra.

O projeto da exposição itinerante Água: uma viagem no mundo do conhecimento, foi apresentado à Unesco, e recebeu chancela do órgão (figura 8, v. anexo), que observou a sintonia da proposta com as recomendações mundiais da década da água e seu forte papel educativo.

A produção de material original demandou 
pesquisa e criatividade, o produto final ficou muito interessante e se tornou objeto de demanda por parte de muitas escolas. O material está sendo programado para reprodução e distribuição nas escolas.

Junto a cada módulo, além do material expositivo, minifilmes e entrevistas localizados em um computador (figura 9), oferecem a possibilidade de imprimir os endereços eletrônicos das Unidades e Órgãos da USP, que desenvolvem atividades acadêmicas e de pesquisa sobre o tema do bloco. Uma tira de papel impressa com as páginas eletrônicas pode ser destacada, sendo levada pelo visitante, de modo que fora do espaço expositivo, onde houver uma conexão com a internet, o visitante pode continuar a obter informações sobre o tema água.

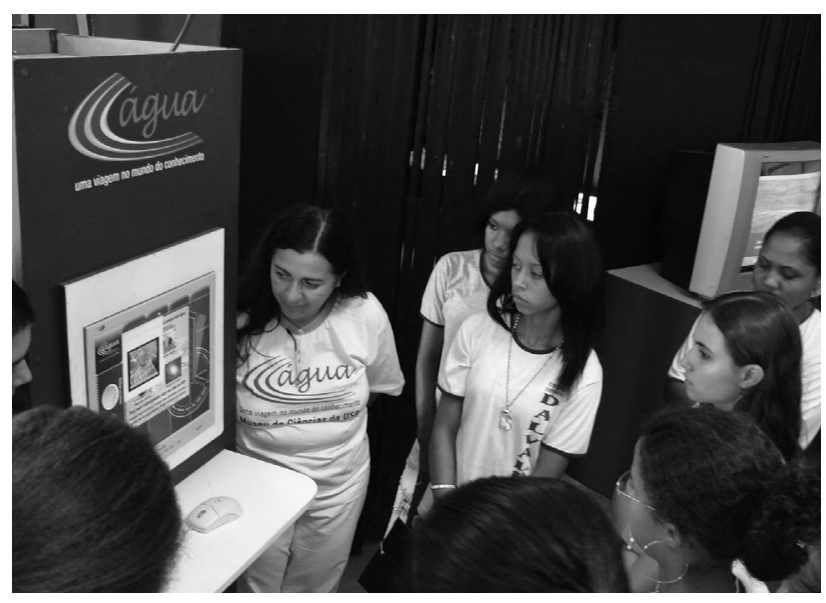

Figura 9 - Computadores disponíveis no espaço expositivo com material interativo e dispositivo para impressão das páginas eletrônicas da USP

Mais de 20 entrevistas com professores, prefeitos, engenheiros sanitaristas, diretores de órgãos, e políticos entre outros, foram concebidas e disponibilizadas nos seis computadores que integram o espaço expositivo da exposição e também podem ser observadas na página eletrônica: www.museudeciencias.usp.br.

Minifilmes (3 a 4 min.) concebidos pelo MGUSP, foram produzidos para reforçar os principais conceitos de cada módulo, sendo apresentados em televisores no formato de looping, versando sobre:

- as propriedades da água, inventário e seu ciclo;

- a vida como um sistema hidratado, água externa e água interna;

- o desenvolvimento do pensamento científico e a revolução industrial;
- a carta da Terra.

O Museu de Arte Contemporânea da USP gerou uma apresentação virtual de suas principais telas com motivos relacionados à água, intitulado "Planeta Azul", que é apresentado em tela formato 42", de modo autoexecutável no espaço expositivo, tornando conhecido parte do acervo de um dos principais $\mathrm{Mu}$ seus da Universidade de São Paulo.

Eventos paralelos e valores locais puderam ser adicionados à exposição em cada local da itinerância, de modo a aproximar os visitantes do tema da exposição, fazendo-o reconhecer a importância da água em sua região e na vida socioeconômica e cultural da região onde ela se apresenta. O visitante pode reconhecer atividades, personalidades e seu cotidiano nos espaços expositivos.

Produções artísticas e técnicas, bem como outras formas de intervenção ocorreram no espaço expositivo, estimulando a comunicação direta e a forma de leitura oferecida aos visitantes, promovendo um melhor aproveitamento do conteúdo.

\section{A ITINERÂNCIA}

A inauguração da exposição ocorreu em São Paulo, na casa de Dona Yayá, um casarão do século $\mathrm{XX}$, que representou um desafio à instalação modular da exposição, que foi inaugurada em outubro de 2005. A proposta da exposição era passar por todos os campi da USP e cidades que estivessem interessadas em recebê-la. A sequência da itinerância apresentou o seguinte trajeto: São Carlos, Pirassununga, Ribeirão Preto, São Sebastião, Piracicaba, Bauru, Cananeia, Araraquara, Taubaté, Foz do Iguaçu e Guaíra, sendo que nesta última cidade ela está sendo apresentada no momento. Os períodos de permanência em cada local encontram-se na tabela I. 
TABELA 1

Cidades, números de visitantes e períodos em que a exposição itinerante Água: uma viagem no mundo do conhecimento marcou presença.

\begin{tabular}{|c|c|c|}
\hline CIDADES & $\begin{array}{l}\text { N. TOTAL DE } \\
\text { VISITANTES }\end{array}$ & PERÍODO \\
\hline São Paulo (SP) & 925 & $\begin{array}{l}27.10 .2005 \\
\text { a 3I.I.2006 }\end{array}$ \\
\hline São Carlos (SP) & $3 \cdot 498$ & $\begin{array}{l}3 \cdot 3 \cdot 2006 \\
\text { a } 3 \cdot 6.2006\end{array}$ \\
\hline Pirassununga (SP) & $3 \cdot 7 \mathrm{I} 2$ & $\begin{array}{l}23 \cdot 6 \cdot 2006 \\
\text { a } 23 \cdot 9 \cdot 2006\end{array}$ \\
\hline Ribeirão Preto (SP) & I2.749 & $\begin{array}{l}7.10 .2006 \\
\text { a 31.12.2006 }\end{array}$ \\
\hline São Sebastião (SP) & 2.104 & $\begin{array}{l}\text { I7.I.2007 } \\
\text { a } 20.4 .2007\end{array}$ \\
\hline Piracicaba (SP) & $4 \cdot 400$ & $\begin{array}{l}8.5 \cdot 2007 \\
\text { a } 14 \cdot 9 \cdot 2007\end{array}$ \\
\hline Bauru (SP) & 2.003 & $\begin{array}{l}21.9 .2007 \\
\text { a } 30.11 .2007\end{array}$ \\
\hline Cananeia (SP) & 4.156 & $\begin{array}{l}5 \cdot \mathrm{I} \cdot 2008 \\
\text { a } 4 \cdot 4 \cdot 2008\end{array}$ \\
\hline Araraquara (SP) & 9.629 & $\begin{array}{l}\mathrm{I} 2 \cdot 4 \cdot 2008 \\
\text { a } 8.7 \cdot 2008\end{array}$ \\
\hline Taubaté (SP) & I. 555 & $\begin{array}{l}\mathrm{I} 4 \cdot 7 \cdot 2008 \\
\text { a } 3 \cdot 10.2008\end{array}$ \\
\hline Foz do Iguaçu (PR) & $4 \cdot 138$ & $\begin{array}{l}\text { IO.IO. } 2008 \\
\text { a IO. } 3.2009\end{array}$ \\
\hline Guaíra (SP)* & 2.500 & $\begin{array}{l}\text { I6.3.2009 } \\
\text { a I6.4.2009 }\end{array}$ \\
\hline $\begin{array}{l}\text { TOTAL REGISTRA- } \\
\text { DO EM LIVRO }\end{array}$ & 51.369 & \\
\hline
\end{tabular}

* Guaíra tem apresentação até 30.08.2009

Os espaços disponíveis para a instalação da exposição foram os mais diversos, desde lugares recortados por cômodos, até espaços amplos, sem divisórias, localizados dentro dos campi universitários e também em locais mais centrais nas cidades anfitriãs (fig. IO a e b, v. anexo).

O público que visitou a exposição em cada cidade e que registrou sua presença nos livros, tem representação na figura II, sendo que o maior público ocorreu na cidade de Ribeirão Preto, onde uma parceria entre a USP, a prefeitura e a casa da Ciência Galileu Galilei, localizada dentro de um bosque central da cidade, ofereceu condições de visitação, tanto para escolares, como para o público geral, muito favoráveis. O esforço realizado pela prefeitura de Araraquara (segundo maior público), em parceria com o Departamento de Água e Esgotos (DAAE) foi intenso e a localização junto à estação de tratamento de água e um parque foi importante, associado à parceria com a Secretaria $\mathrm{Mu}$ nicipal de Educação.

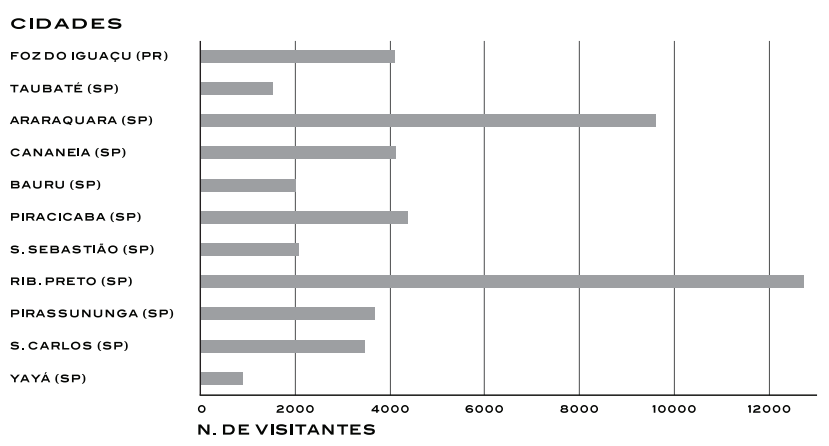

Figura II - Distribuição do público geral nas cidades por onde a exposição marcou presença

Do número total de visitantes, a maioria foi representada pelo público escolar (figura I2).

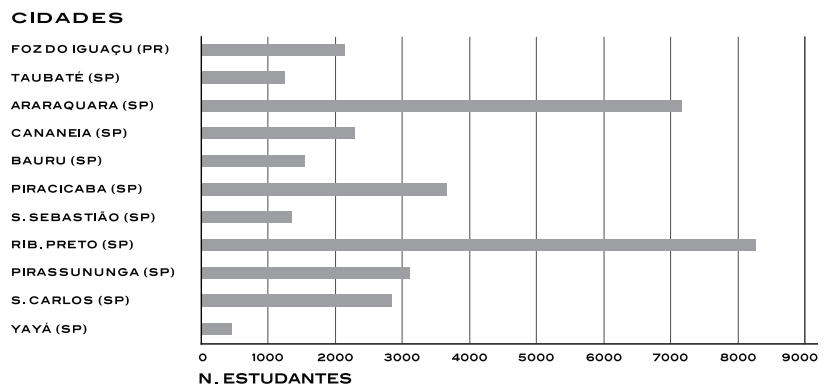

Figura 12 - Número de estudantes que visitaram a exposição em cada cidade visitada

Em todos os locais, o público escolar representou mais de $50 \%$ dos visitantes (figura I3).
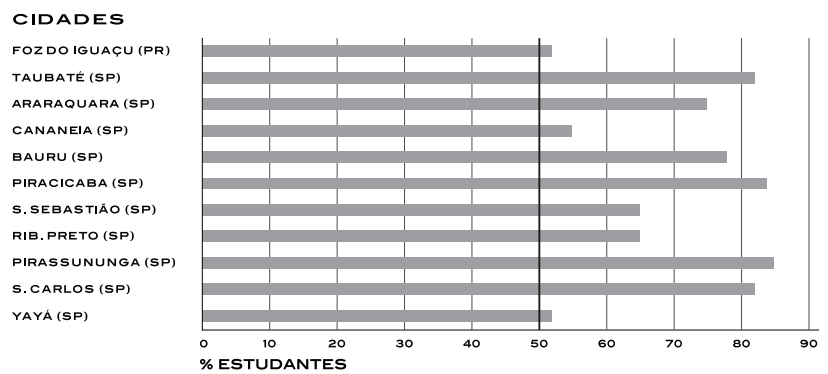

Figura I3 - Porcentagem de estudantes nas cidades de itinerância da exposição Água. 
A abrangência regional foi verificada pelo registro de procedência nos livros de visitantes atingindo as regiões sinalizadas (figura I4), sendo também observados registros de cidades mais distantes, visitantes de outros estados e até mesmo de outros países, em pequeno número, mas observados em todas as localidades.

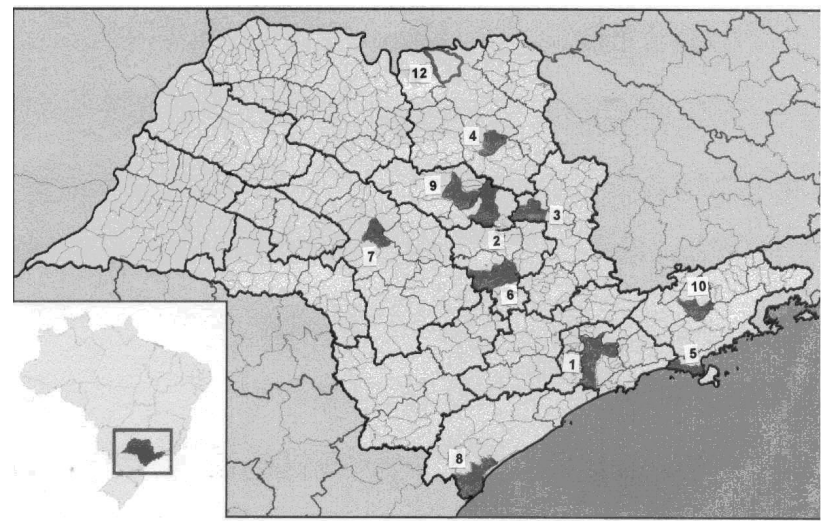

Figura I4 - Municípios do estado de São Paulo onde a exposição se apresentou.

A figura I4 indica os municípios do estado de São Paulo onde a exposição se apresentou, por ordem cronológica: São Paulo (I); São Carlos (2); Pirassununga (3); Ribeirão Preto (4); São Sebastião (5); Piracicaba (6); Bauru (7); Cananeia (8); Araraquara (9); Taubaté (IO) e Guaíra (I2), onde se apresenta de I6/3/2009 a 30/8/2009. Foz do Iguaçu no estado do Paraná (II), logicamente não está presente neste mapa. Observa-se, assim, que o público-alvo atingiu escolares e população geral como proposto no projeto da exposição.

\section{WORKSHOPS DE TREINAMENTO DOS MONITORES}

\section{PARA A EXPOSIÇÃO ÁGUA, EM CADA LOCAL}

De 2006 a 2009 foram realizados onze workshops, um em cada cidade do interior do estado de São Paulo, a saber: São Carlos, Pirassununga, Ribeirão Preto, São Sebastião, Piracicaba, Bauru, Cananeia, Araraquara, Taubaté e Guaíra, além de Foz do Iguaçu, no estado do Paraná. Em cada evento, foram escolhidos e treinados alunos das Unidades USP de cada cidade e também estagiários vinculados às Prefeituras. Os alunos treinados receberam certificados do workshop e ao final do monitoramento, os estagiários receberam certificados de monitoria, de forma que houve uma contribuição à qualificação profissional e ao treinamento de jovens dos locais por onde a exposição passou. 
TABELA 2

Workshops realizados e monitores capacitados em cada cidade de 2006 a 2009.

\begin{tabular}{|c|c|c|c|c|c|}
\hline & LOCAL & PERÍODO & INTEGRAÇÃO & PARTICIPANTES & $\begin{array}{l}\text { N. DE MONITORES } \\
\text { CAPACITADOS }\end{array}$ \\
\hline $\mathrm{I}^{\circ}$ Workshop & São Garlos & II e I2.3.2006 & $\begin{array}{l}\text { São Paulo/ } \\
\text { São Carlos }\end{array}$ & $\begin{array}{l}\text { Equipe MG, alunos de São } \\
\text { Paulo, alunos e professo- } \\
\text { res de São Carlos }\end{array}$ & 6 \\
\hline $\begin{array}{l}2^{\circ} \text { Workshop } \\
\text { (duas fases) }\end{array}$ & $\begin{array}{l}\text { São Carlos e } \\
\text { Pirassununga }\end{array}$ & $\begin{array}{l}\text { 3.6.2006- } \\
\text { São Carlos; } \\
22.6 .2006- \\
\text { Pirassununga }\end{array}$ & $\begin{array}{l}\text { São Paulo/ } \\
\text { São Carlos/ } \\
\text { Pirassununga }\end{array}$ & $\begin{array}{l}\text { Equipe MC, alunos de São } \\
\text { Paulo, alunos e Professo- } \\
\text { res de São Carlos e alunos } \\
\text { de Pirassununga }\end{array}$ & 4 \\
\hline $\begin{array}{l}3^{\circ} \text { Workshop } \\
\text { (duas fases) }\end{array}$ & $\begin{array}{l}\text { Pirassununga e } \\
\text { Ribeirão Preto }\end{array}$ & $\begin{array}{l}23 \cdot 9 \cdot 2006- \\
\text { Pirassununga; } \\
6.10 .2006- \\
\text { Ribeirão Preto }\end{array}$ & $\begin{array}{l}\text { São Paulo/ } \\
\text { Pirassununga/ } \\
\text { Ribeirão Preto }\end{array}$ & $\begin{array}{l}\text { Equipe MC, alunos de São } \\
\text { Paulo, alunos de Pirassu- } \\
\text { nunga e alunos } \\
\text { e professores de Ribeirão } \\
\text { Preto }\end{array}$ & 22 \\
\hline $4^{\circ}$ Workshop & São Sebastião & I6 e I7.I. 2007 & $\begin{array}{l}\text { São Paulo/ } \\
\text { São Sebastião }\end{array}$ & $\begin{array}{l}\text { Equipe MC, alunos de } \\
\text { São Paulo e professores e } \\
\text { alunos de São Sebastião e } \\
\text { monitores da prefeitura }\end{array}$ & I5 \\
\hline $5^{\circ}$ Workshop & Piracicaba & 8.5 .2007 & $\begin{array}{l}\text { São Paulo/ } \\
\text { Piracicaba }\end{array}$ & $\begin{array}{l}\text { Equipe MC, alunos de São } \\
\text { Paulo, professores, alunos } \\
\text { e funcionários } \\
\text { de Piracicaba }\end{array}$ & IO \\
\hline $6^{\circ}$ Workshop & Bauru & $21.9 \cdot 2007$ & $\begin{array}{l}\text { São Paulo/ } \\
\text { Bauru }\end{array}$ & $\begin{array}{l}\text { Equipe MC, alunos de São } \\
\text { Paulo, professores, alunos } \\
\text { e funcionários de Bauru }\end{array}$ & 20 \\
\hline $7^{\circ}[$ Workshop] & Cananeia & 3.I.2008 & $\begin{array}{l}\text { São Paulo/ } \\
\text { Cananeia }\end{array}$ & $\begin{array}{l}\text { Equipe MG alunos de São } \\
\text { Paulo, alunos do IOUSP, } \\
\text { funcionários do IO e da } \\
\text { prefeitura. }\end{array}$ & 20 \\
\hline $8^{\circ}$ Workshop & Araraquara & IO e II. 4.2008 & $\begin{array}{l}\text { São Paulo/ } \\
\text { Araraquara }\end{array}$ & $\begin{array}{l}\text { Equipe MC, alunos de São } \\
\text { Paulo, alunos de Arara- } \\
\text { quara e funcionários do } \\
\text { DAAE }\end{array}$ & 6 \\
\hline $9^{\circ}$ Workshop & Taubaté & 10.7 .2008 & $\begin{array}{l}\text { São Paulo/ } \\
\text { Taubaté }\end{array}$ & $\begin{array}{l}\text { Equipe MG, alunos de São } \\
\text { Paulo, alunos, professores } \\
\text { e funcionários da UNI- } \\
\text { TAU }\end{array}$ & 5 \\
\hline 10 ${ }^{\circ}$ Workshop & Foz do Iguaçu & II.IO. 2008 & $\begin{array}{l}\text { São Paulo/ } \\
\text { Foz do Iguaçu }\end{array}$ & $\begin{array}{l}\text { Equipe MG, alunos de Foz } \\
\text { do Iguaçu e funcionários } \\
\text { do Ecomuseu de Itaipu }\end{array}$ & 8 \\
\hline $\mathrm{II}^{\circ}$ Workshop & Guaíra & 16.3 .2009 & $\begin{array}{l}\text { São Paulo/ } \\
\text { Guaíra }\end{array}$ & $\begin{array}{l}\text { Equipe MG, alunos e pro- } \\
\text { fessores de Guaíra } \\
\text { e Barretos }\end{array}$ & 25 \\
\hline TOTAL & & & & & 140 \\
\hline
\end{tabular}


Em São Paulo foram treinados três monitores para atuar no Centro de Preservação Cultural da USP.

A frequência nos workshops foi diversificada (figura I5, v. anexo), contemplando alunos da rede pública, alunos USP, funcionários das prefeituras e professores. A capacitação e a monitoria proporcionaram experiência, divulgação de ciência, oferecendo certificados emitidos pelo Museu de Ciências da USP, que em muitos casos contribuíram ao engajamento em atividades profissionais de vários monitores.

\section{DA DIVULGAÇÃO NA MÍDIA}

Mais de 50 entrevistas foram geradas em meio impresso e mais de 20 entrevistas em rádios e TVs foram realizadas para a divulgação da exposição.

\section{DOS PRODUTOS GERADOS}

A exposição foi acompanhada por eventos paralelos, produção de minifilmes, entrevistas, cartilhas e criação de personagens.

\section{DISCUSSÃO}

Junto à itinerância da exposição houve a criação de um estreitamento entre os parceiros da Universidade nos diversos campi e ainda mais dois produtos: a) a formação de recursos humanos junto à Universidade (alunos USP), treinados por meio de workshops na monitoria da exposição e na divulgação científica, permitindo a prática da popularização das ciências e treinando jovens para a comunicação científica; b) a aproximação de entidades, tais como prefeituras, outras universidades e empresas, que sediaram a exposição e fazendo-a ter oportunidade de treinar pessoas da comunidade local na divulgação científica, capacitando-as à monitoria $\mathrm{e}$ permitindo uma aproximação maior da Universidade. As crianças e os professores foram grandes frequentadores da exposição nos diversos campi e cidades por onde passou. Houve estímulo de parcerias.

O modelo diferenciado de exposição teve como missão inicial passar pelos diversos campi da Universidade, começando por São Paulo, de forma mais modesta e expandindo à medida em que passava pelas demais cidades onde a USP possui sede. A itinerância representou não somente a recepção da exposição pelos campi, mas representou também parcerias com outras instituições, sobretudo junto às prefeituras.
Seu sistema é diferenciado, ou seja, uma exposição moderna, atraente e, no caso de aspectos de montagem, uma exposição modular, que se adequa a diferentes espaços expositivos, desde casarões até amplos espaços livres e modernos. A exposição tem um perfil de atuar na capacitação de jovens como monitores em ações educativas nestes espaços não-formais, juntando valores locais à exposição, aproximando o visitante dos valores socioeconômicos e culturais locais, catalisados pelo tema água, promovendo o resgate e a preservação da cultura em cada sítio por onde a exposição passou. A capacitação da comunidade local, composta ora por alunos USP dos campi próximos, ora por alunos de outras instituições ou funcionários municipais, em locais onde não havia campus USP, em muitos casos representou uma oportunidade de capacitação para atuação profissional no campo da monitoria de exposições, atividades educativas em espaços não formais, ação junto à secretaria de Educação, turismo entre outros. Alguns recursos humanos foram assimilados para o trabalho ou para estágios mais prolongados, após a experiência junto à exposição itinerante.

A parceria com a Universidade de São Paulo, em muitos locais representou a realização de uma das metas da USP, que dispõe sobre a proximidade à comunidade. O conhecimento da USP para muitos foi inédito, no sentido de saber que ela é rica em patrimônio, oferecendo além do ensino, inovações em pesquisa e extensão de serviços diretamente para a sociedade.

A exposição iniciou sua itinerância partindo de São Paulo, em outubro de 2005 , onde permaneceu por três meses, seguindo para o campus de São Carlos, onde ficou na escola de Engenharia.

O trabalho com as delegacias e secretarias de ensino, foi articulado de modo a complementar os conteúdos disciplinares tratados em sala de aula.

As atividades paralelas geraram peças teatrais, oficinas diversas, palestras, cartilhas para acompanhar a temática, de acordo com a potencialidade do grupo anfitrião e da criatividade das equipes de apoio.

Existe o fornecimento de atestados para as oficinas de capacitação e para a monitoria, com as horas de trabalho. A estratégia permite o contato com diferentes equipes e órgãos abrindo uma frente para a recepção de outras exposições da USP, de outros acervos e museus que dispõem de exposições itinerantes sob diversos temas. O contato e a viabilização da via de itinerância é facilitada por esta experiência inicial. 


\section{CONCLUSÃO}

A exposição Água: uma viagem no mundo do conhecimento apresenta, de maneira objetiva e moderna, o desenvolvimento do planeta Terra desde sua geomorfologia, com o surgimento da água, até o atual mundo tecnológico em que vivemos. A exposição é dividida em blocos temáticos que abordam: A Água e a Terra, Água e Vida, Água e Civilização, Água e Tecnologia e Cuidados e Preservação.

A questão ambiental é abordada como um convite ao público para tornar-se responsável pelo meio em que vive.

A exposição apresenta conteúdo em diversos formatos, contemplando objetos infográficos e recursos multimídia, buscando a inserção do visitante no mundo da complementação do conhecimento via virtual e incentiva o uso da multiplicidade de recursos disponíveis para a difusão da informação.

A exposição itinerante no formato apresentado representou e representa, ainda, uma ferramenta forte que contribui: à educação complementar em espaços não formais; à capacitação de recursos humanos em diversos pontos do país e não somente dentro da USP; à aproximação da Universidade à sociedade; à divulgação do potencial da Universidade e; também, ao estreitamento de relações entre os próprios integrantes da USP.

A iniciativa oferece espaço de produção de materiais didáticos e de geração de conhecimento, valorizando o patrimônio científico-cultural sob a guarda da Universidade, e também permite a integração daqueles abrigados nas diversas cidades.

A exposição nestes moldes representa a construção de elo forte entre as sedes pelas quais a exposição passou, abrindo caminho para outras exposições da USP, criando, assim, um roteiro de parceiros que podem receber não só exposições, mas também outras atividades que a Universidade dispõe, mostrando a proximidade da Universidade com a sociedade.

A geração de cartilhas, minifilmes, entrevistas, peças de teatro, jogos educativos entre outros, representa um conjunto forte de produtos que mantiveram a USP na mídia em mais de uma centena de notícias divulgadas sobre a exposição Água: uma viagem no mundo do conhecimento até o momento.

O modelo desenvolvido pelo Museu de Ciências da USP pode ser adotado para o desenvolvimento de outras temáticas multidisciplinares nos mesmos padrões, permitindo a atualização e o diálogo com os diversos tipos de público, com forte ação sobre o público estudantil e professores. As parcerias contribuem à divulgação nacional e internacional, constituindo importante componente ao sucesso dos eventos, como é o caso verificado nas parcerias que envolveram órgãos da educação estadual e municipal.

\section{REFERÊNCIAS BIBLIOGRÁFICAS}

CoCEx. RESOLUÇÃO CoCEx 4929, de 20 mai. 2002. Baixa o regimento do Museu de Ciências da Universidade de São Paulo, definindo, regulamentando suas atividades e dando outras providências. D.O.E. 22 mai. 2002. Disponível em: 〈www.museudeciencias.usp.br〉.

DIAZ, L. A. B. \& EGIDO, A. DEL. Les musées des sciences sur l' internet. In: Museum International. Paris, Unesco, n. 204 (v. 5I, n. 4, I999), 2000. p. 35-4I. ISSN 0304-3002.

MIRABITO, M. A. Las nuevas tecnologias de la comunicación. Barcelona, Gedisa, I998.

SORIA, I. Las nuevas tecnologia. In: Montañés, C.; Antoranz, M. A.; Blanco, T. et al. El museu - un espacio didáctico y social. Espanha, Mira editores, 200I. I73 p. ISBN 84-8465-082-0.

ONU. United Nations General Assembly. Dec. 2003. Disponível em: 〈www.un.org/waterforlife〉.

ONU. Water for the life-pdf. Published by Un Departament of Public Information. 20 p., mar. 2005. Disponível em: <www.un.org/waterforlifedecade>.

WAGENSBERG, J. A una musologia total. Los Cursos del Museu, 2008. Barcelona, Cosmo Caixa/ Fundación la Caixa, 2008 


\section{Bloco I - Origem cósmica da} Água e Água no Planeta Terra

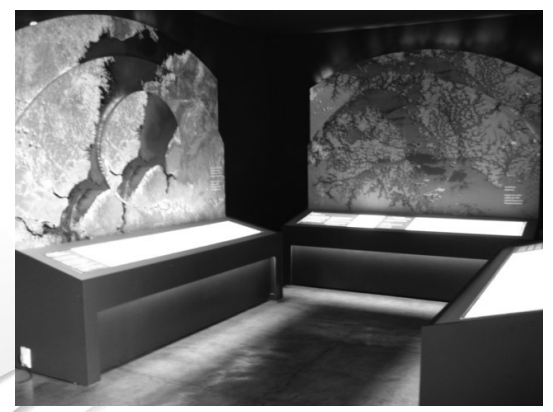

Apresenta a substância água com todas as suas propriedades especiais, como a Terra acomoda e movimenta a água, distribuindo 0 calor, possibilitando as diversas configurações climáticas e assim, torna-se um planeta diferenciado.

\section{Bloco II - Água e a vida}

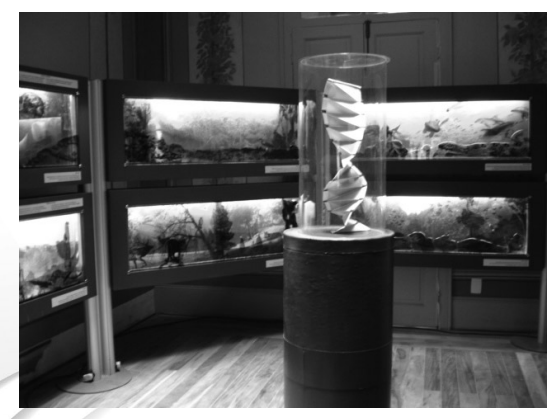

A sopa primordial, o RNA

o DNA, a origem da vida.

$A$ vida, um sistema hidratado

individualizado, a troca de água entre o meio interno e meio externo. 


\section{Bloco III - Água e as civilizações}

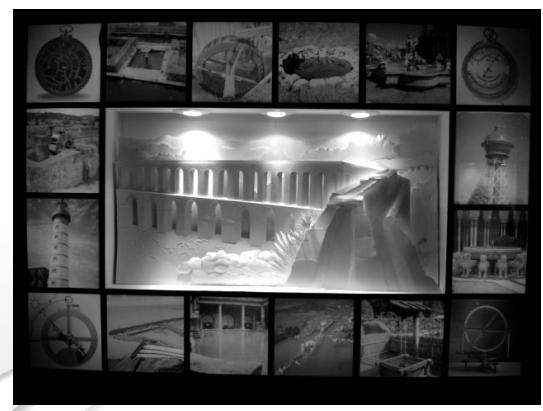

0 relacionamento do homem com a água ao longo da história.

Desenvolvimento tecnológico

- arquitetura, transporte e distribuição transporte $\mathrm{e}$ distribuição.

Produção cultural - mitologia, religião e artes.

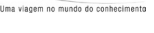

Figura 4 - Temática do bloco III

\section{Bloco IV - Água e a Revolução Industrial}

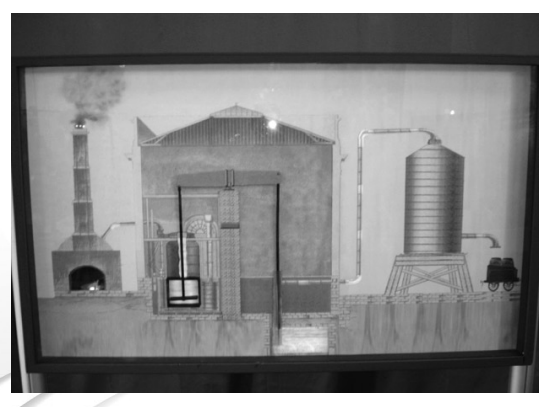

Desenvolvimento do pensamento científico baseado no método.

A água passa a ser considerada um importante recurso energético para os primeiros equipamentos em produção em larga escala.

Figura 5 - Temática do bloco IV 


\section{Bloco V - Água e o Impacto Ambiental}

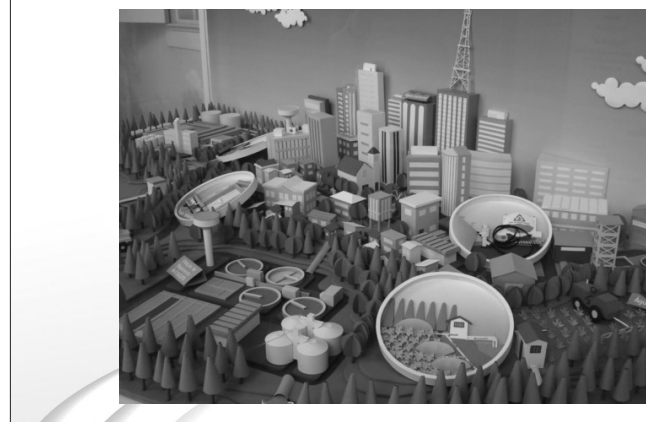

Com o desenvolvimento industrial, aumento da população e o uso indiscriminado da água, surgem problemas como a escassez e alterações na sua qualidade, e na sua movimentação na terra, chamando atenção para 0 impacto ambiental.

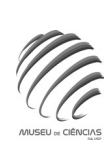

Figura 6 - Temática do bloco V

\section{A USP e as pesquisas relacionadas à água}

As universidades têm a missão de fomentar o desenvolvimento científico e tecnológico em benefício da sociedade e a USP participa desse processo. Busca soluções para os problemas contemporâneos relacionados à água e compartilha esse conhecimento com a sociedade por meio da exposição de seu Museu de Ciências.

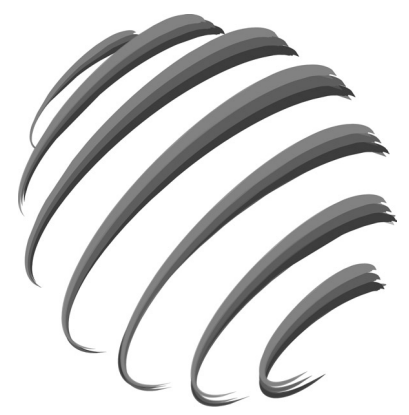

MUSEU DE CIÊNCINS

Figura 7 - A Universidade e seu papel junto ao tema água. 


\section{Museu de Ciências da USP Exposição Itinerante}

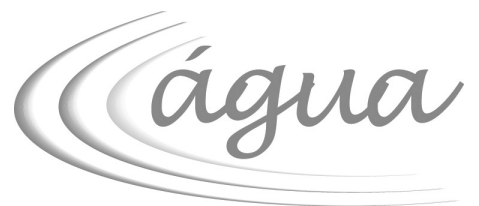

Uma viagem no mundo do conhecimento

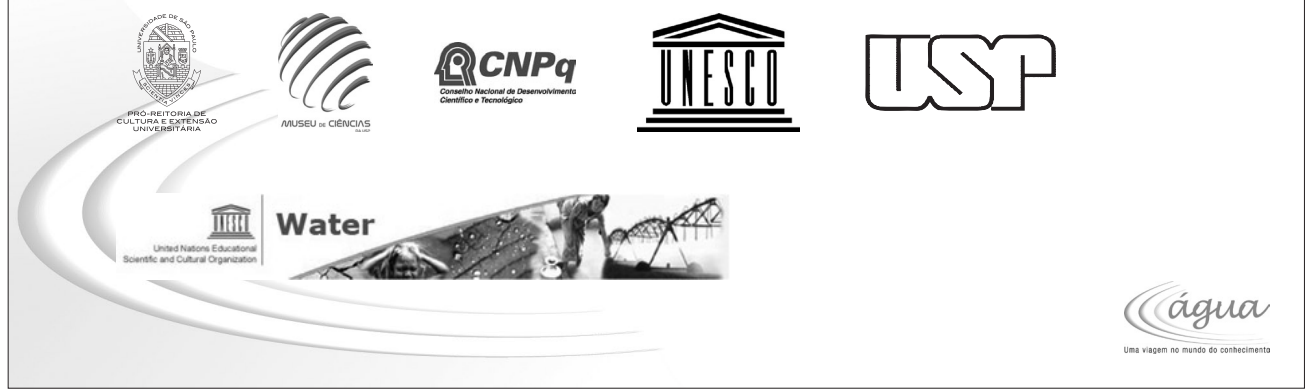

Figura 8 - Organizadores e parceiros da exposição itinerante Água: uma viagem no mundo do conhecimento

\section{Exposição itinerante 2005/2007} Água: uma viagem no mundo do conhecimento
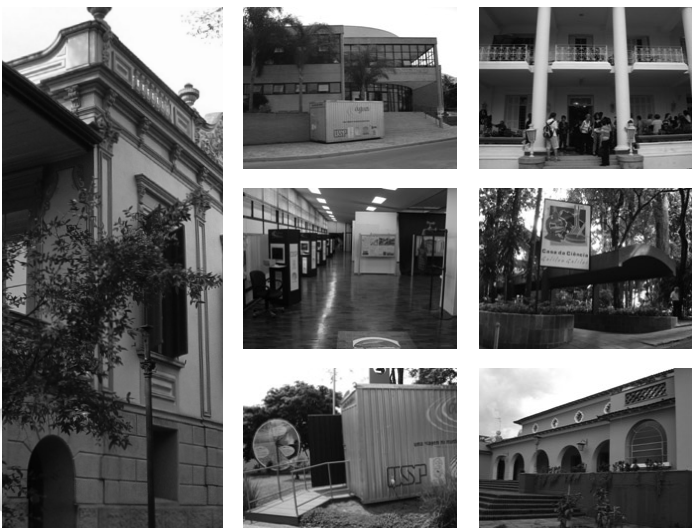

$1^{\text {a }}$ Fase - São Paulo

Casa da Dona Yayá

$2^{\mathrm{a}}$ Fase - São Carlos

Campus I - USP São Carlos

$3^{\text {a }}$ Fase - Pirassununga

Centro de Eventos da USP
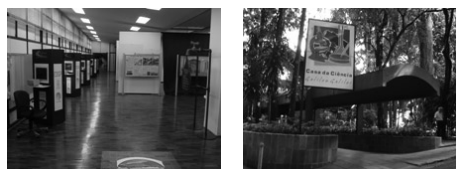

de Pirassununga

$4^{\mathrm{a}}$ Fase - Ribeirão Preto

Casa da Ciência Galileu Galilei

$5^{\text {a }}$ Fase - São Sebastião

Teatro Municipal de São Sebastião

\section{$6^{\text {a }}$ Fase - Piracicaba}

Museu e Centro de Ciências,

Educação e Artes Luiz de Queiroz

$7^{\text {a }}$ Fase - Bauru

Centrinho -FOB

Figura IOa - Locais onde a exposição Água teve passagem. 
Exposição itinerante 2005/2007 Água: uma viagem no mundo do conhecimento
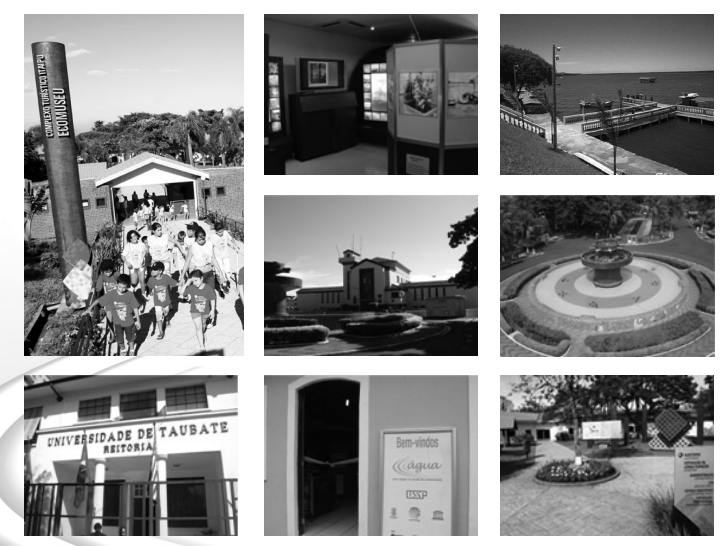

$8^{a}$ Fase - Cananeia-SP

Casa Caiçara - Prefeitura de Cananeia 4/1/2008

$9^{\text {a }}$ Fase - Araraquara-SP

Estação de tratamento de água - DAEE $11 / 4 / 2008$
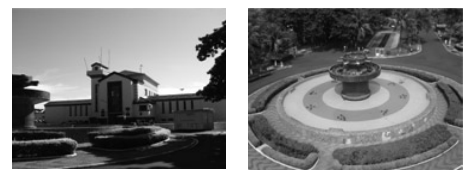

$10^{a}$ Fase - Taubaté-SP

Faculdade de Arquitetura - UNITAU

$11 / 07 / 2008$

$11^{\text {a }}$ Fase - Foz do Iguaçu-PR Ecomuseu de Itaipu - Binacional
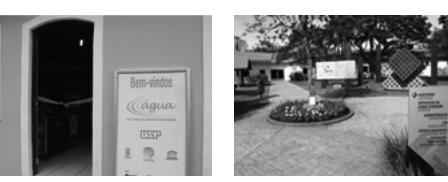

$10 / 10 / 2008$

$12^{\mathrm{a}}$ Fase - Guaíra-SP

Oribis Club - Prefeitura de Guaíra $16 / 3 / 2009$

Figura Iob - Locais onde a exposição Água teve passagem.

\section{Workshops de treinamento dos monitores}
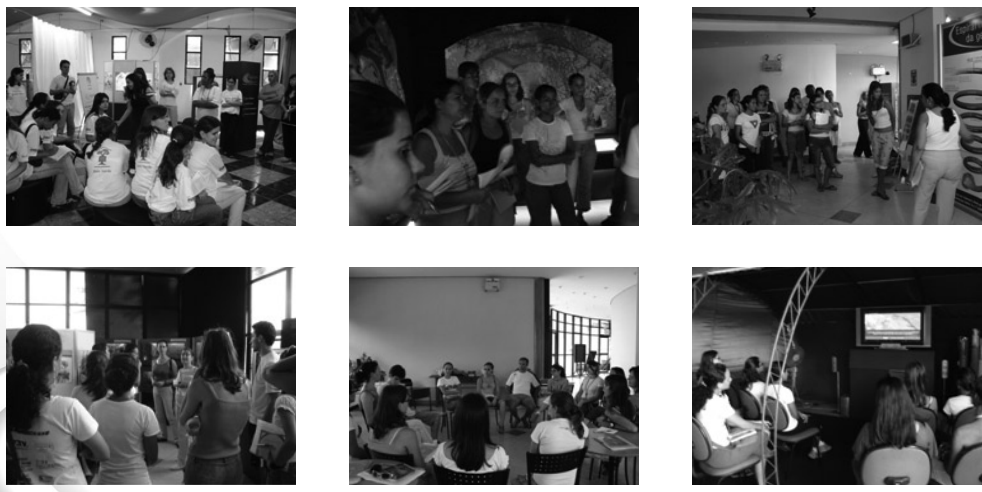

Figura I5 - Workshops da Exposição Água: uma viagem no mundo do conhecimento, em várias cidades. 